\title{
Clinical effects of consuming milk and its products
}

\section{By I. Macdonald, Department of Physiology, Guy's Hospital Medical School, London $S E_{1}{ }_{9} R T$}

There is no need to catalogue the nutritional properties of milk as the value of the proteins, vitamins, minerals, etc., in milk is well known and accepted, and the beneficial effects resulting from the ingestion of these compounds have long been described. The protein of milk is still used in the treatment of malnutrition in children both in hospital and in large communities. It is routine advice, accepted by government by the provision of a subsidy, to give extra milk in pregnancy and lactation and to the preschool and school child. In 1976 dairy foods (excluding butter) in the US contributed only $11.2 \%$ of food energy available, but provided $21.9 \%$ of the protein and $75.0 \%$ of the calcium intake (Marston \& Friend, 1976). It is with the less well known aspects of the clinical consequences of consuming milk, excluding milk fat, that this presentation is concerned.

\section{Protein}

Intolerance. It was in 1958 (Davies) that milk allergy in infancy was first reported in the United Kingdom, and it is considered to be the most easily diagnosed as well as the most severe of food allergies in childhood and as the children get older the symptoms become more insidious and less related to the gastrointestinal tract (Freier, 1976). Food allergy after the first year of life may be on the increase with about one child in 200 affected but what proportion is due to milk or to various additives, preservatives, drugs, etc., due to the child's widening dietary experience, is not known (Freier, 1976).

As there are multiple proteins in milk, the reactions of those who are intolerant of any one or more of these proteins are varied and little work seems to have been done to identify which of the proteins is the major offending factor. Most information about intolerance to milk proteins refers to children during the first two years of life. The incidence of the condition in this age group seems unsure but values from $0.4 \%$ to $7.5 \%$ have been published (Heiner, Sears \& Kniker, 1962; Gerrard, MacKenzie, Goluboff, Garson \& Maningas, 1973). The symptoms may involve the gastrointestinal tract, with diarrhoea, vomiting, colic, or affect the skin or respiratory tract and the diagnosis is made with a degree of certainty when the symptoms disappear when milk is removed from the diet and reappear when milk is again included in the diet. In most cases milk ingestion ceases to give rise to symptoms when the child is over two years of age.

A different type of intolerance to milk protein from that just described is an intolerance to fresh milk, as changing from fresh to dried milk results in disappearance of the symptoms. The clinical picture described (Nutrition Reviews, 
1973) consists of an iron deficiency anaemia, reduced concentrations of serum albumin and abnormality of the intestinal mucosa. The anaemia may well be due to bleeding from the gut mucosa leading to a loss of blood in the faeces (Wilson, Lahey \& Heiner, 1974). No evidence about its incidence or the amount of fresh milk that can be consumed without signs or symptoms seems to be known.

In view of the clinical problems created by milk ingestion in children, the Committee on Nutrition of the American Academy of Pediatrics (1974) issued a statement summarising its current views on milk as a nutrient. It stated that cows' milk was a valuable substitute for human milk and a useful food for older infants and young children, and though it supplied a large proportion of essential nutrients and energy, it was not an essential component of the diet for anyone whose diet is otherwise adequate (Widdowson \& McCance, 1954). The Committee also stated that the evidence at present is insufficient to warrant discouraging programmes for increasing the supply and consumption of milk in developing countries where childhood malnutrition is rife. The statement also outlined three common situations in paediatric practice which may call for a restriction of milk intake: (i) iron deficiency anaemia, as milk is a very poor source of iron; (ii) the 1-3 year old who 'won't eat'. This is frequently due to the large daily milk consumption that accounts for $90 \%$ or more of the energy intake; (iii) the healthy but constipated child should use skimmed milk to reduce the formation of insoluble calcium soaps and thus make the stools softer.

Suitability of milk protein. Liquid milk contains approximately $3.5 \%$ protein of which $80 \%$ is casein, and the remainder is whey comprising albumin and globulin (Gordon \& Kalan, 1974). The amino acid pattern of whole milk protein contains more indispensable amino acids than a reference protein (Food and Nutrition Board, 1959). Casein alone has a lower biological value than whey proteins because the sulphur-containing amino acids are limiting in casein, but when the two groups are together as in milk they obviously complement each other.

The casein in milk precipitates when it enters the stomach and this solid mass is then digested by pepsin, little of which is present in the stomach of infants, and its digestion is therefore mainly by trypsin from the pancreas. The advantage of converting the casein to an insoluble form is not clear but despite that, attempts to prevent this by dilution or by precipitating the calcium ions is common infant feeding practice.

The adequacy of milk protein for infants has been shown (Mellander, Vahlquist \& Mellbin, 1959) in a study that found that babies fed on cows' milk preparations were as healthy as those that were breast-fed and if anything the artificially fed infants were often larger than the breast-fed. This may be a disadvantage for two reasons, one being that the overweight baby may be more likely to be an overweight child and adult, and the other is the more remote possibility that an early onset of maturity brought about by rapid growth has been associated in animals with reduced longevity (McCay, 1955). On the other hand, retarded growth seems to be related to retarded mental ability (Tanner, 1955).

Milk protein as a food supplement. Most breakfast cereals are low in protein and 
high in starch and the addition of milk converts a nutritionally inadequate food into a more balanced food with the possible exception of ascorbic acid which is low in cows' milk. It is not the fat in milk that is important in this situation but the milk protein, and though less acceptable psychologically, skimmed milk would therefore be adequate to add to breakfast cereals, 'milk' puddings, etc.

\section{Carbohydrate}

The carbohydrate in milk is lactose and though there are advantages osmotically in having a disaccharide rather than a monosaccharide in solution it is difficult to understand why galactose rather than glucose should be the other monosaccharide accompanying glucose in the lactose molecule. Evidence of the non-essentiality of galactose is to be found in infants with lactase deficiency because, assuming this condition is diagnosed early, these infants do not seem to be in any way different as children and adults to those with lactase present in the intestinal wall.

Lactose and calcium absorption. One possible role for lactose is that it aids in the absorption of calcium (Wasserman \& Lengemann, I960) and in those animals with rapid bone growth in early life this may be essential. There seem to be some conflicting findings when this suggestion is investigated (Urban \& Pena, 1975; Schaafsma \& de Waard, 1978). Certainly the means whereby dietary lactose might improve calcium absorption remains unknown.

Lactose intolerance. Lactose intolerance was first described in infants in the UK in 1959 (Holzel, Schwartz \& Sutcliffe) though complete congenital lactase deficiency is rare. Lactase deficiency of a temporary nature is sometimes found secondary to gastrointestinal disorders and recovers when the primary disorder is relieved.

Lactase deficiency is much more common in adults and may indeed be considered to be a physiological state. The incidence of lactase deficiency is related to race and geography and is seen in 2-8\% of West Europeans and over $60 \%$ in those of Mediterranean, African or Asian origin (Committee on Nutrition, American Academy of Pediatrics, 1974). A quotation from the ARC/MRC report on Food and Nutrition Research (1974) summarises the situation clearly and concisely, '. . little attention has yet been placed on the levels of milk intake which can be tolerated by children and adults with low lactase activities: encouraging milk drinking in these subjects may be unwise since even in the absence of symptoms absorption of energy in the small intestine may be limited; malabsorption of other dietary constituents may occur secondary to an increased flow of fluid into the colon.'

Galactose. Galactose, like glucose, is actively absorbed across the wall of the intestine and both these monosaccharides share a common absorption mechanism. When galactose is present with glucose, as is normal on the hydrolysis of lactose, the serum levels of galactose do not increase much, but when an equivalent amount of galactose is taken without the glucose then the serum concentration of galactose more than doubles (Stenstam, 1946) and this has been interpreted as evidence of 
competition with glucose for the common absorptive mechanism. However, glucose does not seem to be thus affected by the presence of galactose.

It is perhaps fortunate that glucose does have this inhibitory role on serum galactose levels as galactose in high blood concentration gives rise to cataract due to the formation of its alcohol (dulcitol) in the lens and the inability of this compound to be removed leads by osmosis to water accumulating in the lens. The effect of galactose on the lens seems to be more marked in the young (Cotlier, I962) and in the rare inborn error of metabolism where blood levels of galactose are high, the children affected have cataract as well as liver damage, and mental retardation (Schwarz, i 975).

The possibility of galactose cataract is obviously remote when it is considered that many children drink I litre of milk a day and thus ingest $25 \mathrm{~g}$ galactose daily, (with glucose) and cataract is rare in children.

Galactose and alcohol. In 1914 it was reported that brandy increased the galactosuria after galactose ingestion (Wagner) and subsequent experiments confirm that at constant amounts of galactose the galactosuria increases with increased alcohol load (Stenstam, 1946). However, there does not seem to be any evidence that alcohol metabolism is influenced by galactose and the traditional advice to drink milk before imbibing alcohol is perhaps based on the effect that milk has in delaying gastric emptying with a consequent slower and longer period of absorption.

\section{Therapeutic uses}

Breast milk substitute. This probably forms the major function of milk in clinical medicine and though extremely important, discussion of this aspect will not be considered here.

Childhood malnutrition. This condition, commonly seen in tropical countries, is usually a protein deficient state and milk protein is a suitable replacement from both physiological and economic aspects.

Convalescence. Due to its apparent ease of digestion, milk is often recommended as a metabolically acceptable food, especially in those who are recovering from gastrointestinal disorders, with its advantage of being able to be taken at frequent intervals and in small quantities with minimal inconvenience. It is perhaps these latter properties that make milk so acceptable in recovery from illness.

Peptic ulcer. Milk is no longer considered to be the dietary item of most value in treating peptic ulcer. The high protein and phosphate content of cows' milk makes it a good buffer and as peptic, and particularly duodenal, ulceration is associated with a high level of gastric acidity continuous intragastric drips used to be given to these patients. Now other methods of treatment are used and it has been suggested that the chronic nature of peptic ulceration with the ingestion of large quantities of milk over years has lead to the high incidence of coronary artery disease in these patients with scurvy and hypercalcaemia as other reported but rare complications.

No mention has been made of milk fat or of the minerals and vitamins always 
present-it took two volumes to include everything (Kon \& Cowie, 1961). However, milk is a sufficiently complex food that it will always have a role in preserving human health and its role in clinical medicine, though in some instances undesirable, is, on balance, both metabolically and psychologically invaluable.

\section{REFERENCES}

Committee on Nutrition, American Academy of Pediatrics (1974). Nutr. Rev. 32, 363.

Cotlier, E. (1962). Archs Ophthal., N.Y. 68, 801.

Davies, W. (1958). Archs Dis. Childh. 33, 265.

Food and Nutrition Board (1959). Improvement of Protein Nutriture. NRC Wash. D.C. Publ. No. 711 .

Food and Nutrition Research (1974). London: HMSO.

Freier, S. (1976). J. Human Nutr. 30, 187.

Gerrard, J. W., Mackenzie, J. W. A., Goluboff, N., Garson, J. Z. \& Maningas, C. S. (1973). Acta paediat. Stockh. 234, 1.

Gordon, W. G. \& Kalan, E. B. (1974). In Fundamentals of Dairy Chemistry, p. 87, 2nd ed. [B. H. Webb, A. H. Johnson \& J. A. Alford, editora]. Westport: Avi Publ. Co.

Heiner, D. C., Sears, J. W. \& Kniker, W. T. (1962). Am. J. Dis. Child. ro3, 634.

Holzel, A., Schwartz, V. \& Sutcliffe, K. W. (1959). Lancet i, 1126.

Kon, S. K. \& Cowie, A. T. (I96I). Milk: The mammary gland and its secretion. New York: Academic Press.

Marston, R. \& Friend, B. (I976). National Food Situation NFS $158,25$.

McCay, C. M. (1 955). In Colloquia on Ageing. [G. E. Wolstenholme \& M. P. Cameron, editors]. London: Churchill.

Mellander, M., Vahlquist, B., \& Mellbin, T. (1959). Acta paediat. Stockh. 48, Suppl. I 6.

Nutrition Reviews (1973). 31, 318..

Schaafsma, G. \& de Waard, H. (1978). Am. f. clin. Nutr. 31, 4 .

Schwarz, V. (1975). Biochem. Soc. Trans. 3, 234.

Stenstam, T. (1946). Acta med. scand. 125, Suppl. I77.

Tanner, J. M. (1955). Growth at adolescence. Oxford: Blackwell.

Urban, E. \& Pena, M. (1975). Am. F. clin. Nutr. $28,431$.

Wagner, F. (1914). Z. klin. Med. 80, 174.

Wasserman, R. H. \& Lengemann, F. W. (1960). F. Nutr. 70, 377

Widdowson, E. M. \& McCance, R. A. (1954). Spec. Rep. Ser. med. Res. Coun. 287.

Wilson, J. F., Lahey, M. E. \& Heiner, D. C. (1974). F. Paediat. 84, 335. 